\title{
A VTST Study of the $\mathrm{H}+\mathrm{O}_{3}$ and $\mathrm{O}+\mathrm{HO}_{2}$ Reactions Using a Six-dimensional DMBE Potential Energy Surface for Ground State $\mathrm{HO}_{3}$
}

\author{
A. Fernández-Ramos and A. J. C. Varandas* \\ Departamento de Química, Universidade de Coimbra, P-3049 Coimbra, Portugal \\ Received: November 9, 2001; In Final Form: February 1, 2002
}

\begin{abstract}
The variational transition state theory (VTST) is used to calculate thermal rate constants for the reactions $\mathrm{H}$ $+\mathrm{O}_{3} \rightarrow \mathrm{OH}+\mathrm{O}_{2}(\mathbf{R} 1)$ and $\mathrm{O}+\mathrm{HO}_{2} \rightarrow \mathrm{OH}+\mathrm{O}_{2}(\mathbf{R} 2)$. Both reactions are studied using a double manybody expansion (DMBE) potential energy surface for ground state $\mathrm{HO}_{3}$. The VTST results are compared with quasiclassical trajectory calculations (QCT) and experiment. Reaction R1 shows a planar transition state which, including the zero-point energy, is $0.16 \mathrm{kcal} \mathrm{mol}^{-1}$ above the reactants. This reaction presents two maxima in the vibrational adiabatic potential, and hence, unified statistical theory in its canonical (CUS) and microcanonical (US) versions has been employed in addition to the canonical (CVT) and microcanonical $(\mu \mathrm{VT})$ variational transition state theories. The results obtained by the CUS and US methods compare well with QCT and experiment. The DMBE potential energy surface predicts that reaction $\mathbf{R} 2$ occurs via oxygen abstraction. Two possible reaction paths were found for this reaction. One path has no transition state with an oxygen angle of attack close to $155^{\circ}$, and the other path presents a transition state with an oxygen angle of attack of about $80^{\circ}$. Because the potential energy surface for this reaction is quite flat, the CVT and $\mu \mathrm{VT}$ methods were used together with an algorithm that reorients the dividing surface to maximize the Gibbs free energy. The VTST results are found to agree reasonably well with experiment and with QCT calculations.
\end{abstract}

\section{Introduction}

The reaction $\mathrm{H}+\mathrm{O}_{3} \rightarrow \mathrm{OH}+\mathrm{O}_{2}(\mathbf{R} 1)$ toghether with $\mathrm{O}\left({ }^{3} \mathrm{P}\right)$ $+\mathrm{HO}_{2} \rightarrow \mathrm{OH}+\mathrm{O}_{2}(\mathbf{R 2})$ play an important role in atmospheric chemistry. Specifically, R1 produces hydroxyl radicals in vibrationally excited states and is responsible for the night sky air glow, whereas $\mathbf{R 2}$ is important in the chemistry of the mesosphere and upper stratosphere. ${ }^{1-5}$ Both reactions have been extensively studied because of their environmental implications, and experimental thermal rate constants are well-known. ${ }^{6-20}$ The recommended value $\mathrm{e}^{21,22}$ for reaction $\mathbf{R} \mathbf{1}$ at room temperature is $2.8 \times 10^{-11} \mathrm{~cm}^{3} \mathrm{~s}^{-1}$ with an estimated Arrhenius activation energy of $0.9 \mathrm{kcal} \mathrm{mol}^{-1}$. The reaction $\mathrm{H}+\mathrm{O}_{3} \rightarrow \mathrm{HO}_{2}+\mathrm{O}$ competes with R1. Yet, its rate constant ${ }^{14,17}$ at room temperature is only about $5.6 \times 10^{-13} \mathrm{~cm}^{3} \mathrm{~s}^{-1}$, which makes it negligible for practical purposes. From the theoretical point of view, thermal rate constants and cross sections have been previously studied with quasiclassical trajectory (QCT) calculations ${ }^{23,24}$ and different quantum mechanical models; ${ }^{25-27}$ for a review on theoretical work which covers this and other four-atom atmospheric reactions, see ref 28 .

Besides the interest of reaction $\mathbf{R} \mathbf{2}$ in atmospheric chemistry, this reaction is also important as a chain breaking step in combustion processes. ${ }^{29}$ Two different mechanisms have been suggested: ${ }^{30}$ (i) direct hydrogen abstraction by the oxygen atom involving a tight transition state

$$
\mathrm{O}+\mathrm{HO}_{2} \rightarrow \mathrm{O} \cdots \mathrm{HO}_{2} \rightarrow \mathrm{OH}+\mathrm{O}_{2}
$$

and (ii) oxygen abstraction via formation of a $\mathrm{HO}_{3}$ complex with no barrier

* To whom correspondence should be addressed. E-mail: varandas@ qtvs1.qui.uc.pt.

$$
\mathrm{O}+\mathrm{HO}_{2} \rightarrow \mathrm{O} \cdots \mathrm{O}_{2} \mathrm{H} \rightarrow \mathrm{OH}+\mathrm{O}_{2}
$$

Several experimental studies have been reported in the literature. ${ }^{9,31-37}$ It has been shown ${ }^{36}$ by ${ }^{18} \mathrm{O}$ isotopic substitution experiments that the reaction proceeds via oxygen abstraction, at least for low temperatures. Thermal reaction rates for this reaction were computed with QCT and approximate quantum models $^{38,39}$ using the DMBE potential energy surface ${ }^{40}$ for ground-state $\mathrm{HO}_{3}$ also employed in the present study (denoted currently $^{23}$ as DMBE I). VTST ${ }^{41}$ has also been applied to this reaction by Setokuchi et al. ${ }^{42}$ using direct ab initio calculations of the potential energy surface.

The major goal of this work is to monitor the performance of VTST for the calculation of thermal rate constants for reactions $\mathbf{R} \mathbf{1}$ and $\mathbf{R} 2$ using the DMBE I potential energy surface of Varandas and $\mathrm{Yu} .{ }^{23} \mathrm{We}$ also compare the VTST calculations with previous theoretical results obtained on the DMBE I potential energy surface.

\section{Potential Energy Surface}

In this work, we utilize the DMBE I potential energy surface for ground state $\mathrm{HO}_{3}$. Because it has been described in detail elsewhere, ${ }^{23}$ we analyze below only the major features of this surface which are related to the reactions object of the present study. For both reactions, the oxygen atoms are labeled as indicated in Figure 1.

The most important features in the study of reaction $\mathbf{R} \mathbf{1}$ are shown in the isoenergy contour plot of Figure 2, which has been obtained by allowing all distances, angles, and dihedrals to partially relax as a function of the $\mathrm{H}-\mathrm{O}_{\mathrm{a}}$ and $\mathrm{O}_{\mathrm{a}}-\mathrm{O}_{\mathrm{b}}$ distances $\left(2.30 \leq R_{\mathrm{O}_{\mathrm{b}} \mathrm{O}_{\mathrm{c}}} / \mathrm{a}_{0} \leq 2.50,90 \leq \theta_{\mathrm{HOO}} / \mathrm{deg} \leq 180,90 \leq \theta_{\mathrm{OOO}} /\right.$ $\left.\operatorname{deg} \leq 130,0 \leq \phi_{\mathrm{HOOO}} / \mathrm{deg} \leq 180\right)$. The hydrogen atom is then 


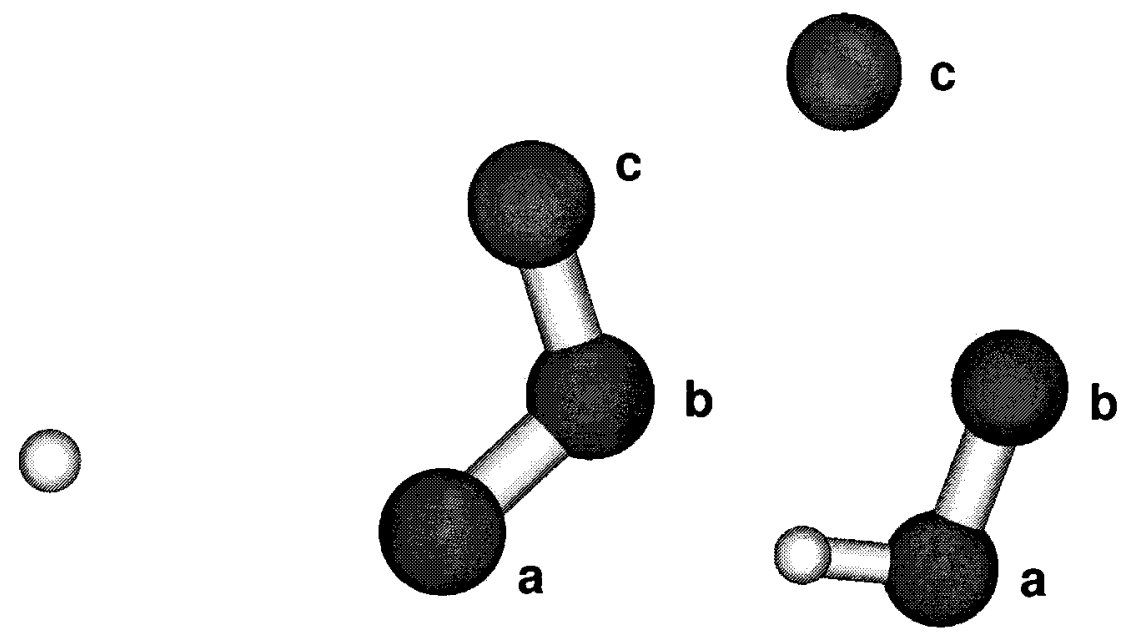

\section{R1}

Figure 1. Numbering of oxygen atoms in reaction R1 (left) and reaction $\mathbf{R 2}$ (right).

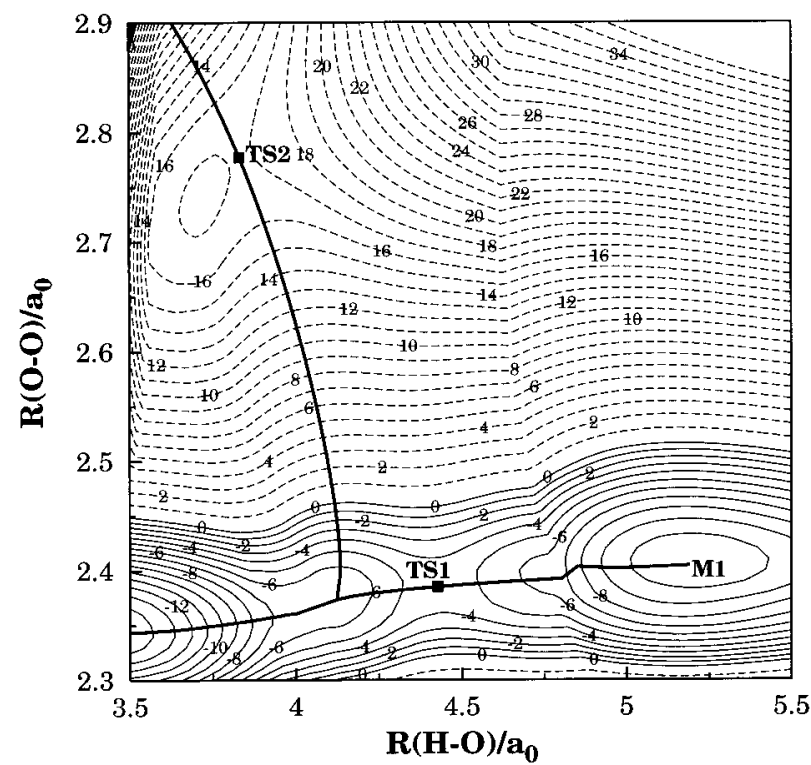

Figure 2. Potential energy surface for reaction R1. The solid contours are equally spaced by $0.1 \mathrm{kcal} \mathrm{mol}^{-1}$ and the dashed contours by 0.25 $\mathrm{kcal} \mathrm{mol}^{-1}$. The zero of energy corresponds to reactants.

found to attack the ozone molecule with a dihedral angle close to $90^{\circ}$, leading to a van der Waals minimum (M1-I) at $d_{\mathrm{H}-\mathrm{O}}=$ $5.19 \mathrm{a}_{0}$. The thick continuous line depicted in Figure 2 joining the van der Waals minimum and product sites through the transition state TS1-I is the minimum energy path (MEP). The geometries and frequencies of these two stationary points are listed in Table 1. The transition state TS1-I lies $0.48 \mathrm{kcal} \mathrm{mol}^{-1}$ below reactants and $0.61 \mathrm{kcal} \mathrm{mol}^{-1}$ above the van der Waals minimum. At $d_{\mathrm{H}-\mathrm{O}}=4.12 \mathrm{a}_{0}$, there is a bifurcation point where the torsion frequency is close to zero. One path is downhill, but the hydrogen atom moves out of the plane of ozone. In the other path, the molecule remains planar, and the bifurcation point is connected to a second transition state (TS2-I) that is 4.23 $\mathrm{kcal} \mathrm{mol}^{-1}$ above the reactants. They both finally join to give $\mathrm{OH}+\mathrm{O}_{2}$ products.

Figure 3 shows the contour plot corresponding to reaction $\mathbf{R} 2$ (oxygen abstraction) as a function of the $\mathrm{O}_{a} \mathrm{O}_{b} \mathrm{O}_{c}$ angle and
TABLE 1: Geometries (Distances in $\mathbf{a}_{0}$, Angles in Degrees), Frequencies (in $\mathbf{c m}^{-1}$ ), and Relative Stabilities (in kcal $\mathrm{mol}^{-1}$ ) of the Stationary Points to Study Reaction R1

\begin{tabular}{|c|c|c|c|c|c|}
\hline & $\mathrm{H}+\mathrm{O}_{3}$ & M1-I & TS1-I & TS2-I & $\mathrm{HO}+\mathrm{O}_{2}$ \\
\hline$R_{\mathrm{HO}_{\mathrm{a}}}$ & & 5.1919 & 4.4276 & 3.8320 & 1.8344 \\
\hline$R_{\mathrm{O}_{\mathrm{a}} \mathrm{O}_{\mathrm{b}}}$ & 2.4037 & 2.4050 & 2.3850 & 2.7772 & \\
\hline$R_{\mathrm{O}_{\mathrm{b}} \mathrm{O}_{\mathrm{c}}}$ & 2.4037 & 2.3995 & 2.3893 & 2.3266 & 2.2818 \\
\hline$\theta_{\mathrm{HO}_{3} \mathrm{O}_{\mathrm{b}}}$ & & 125.1 & 122.7 & 121.5 & \\
\hline$\theta_{\mathrm{O}_{\mathrm{a}} \mathrm{O}_{\mathrm{b}} \mathrm{O}_{\mathrm{c}}}$ & 116.8 & 116.3 & 114.6 & 110.0 & \\
\hline$\phi_{\mathrm{HO}_{\mathrm{a}} \mathrm{O}_{\mathrm{b}} \mathrm{O}_{\mathrm{c}}}$ & & 97.1 & 0.0 & 0.0 & \\
\hline \multicolumn{6}{|c|}{ Frequencies } \\
\hline$\omega_{1}$ & 1135 & 1140 & 1173 & 1276 & 3744 \\
\hline$\omega_{2}$ & 1089 & 1056 & 1028 & 933 & 1577 \\
\hline$\omega_{3}$ & 716 & 737 & 776 & 529 & \\
\hline$\omega_{4}$ & & 424 & 318 & 437 & \\
\hline$\omega_{5}$ & & 167 & 99 & 33 & \\
\hline$\omega_{6}$ & & 69 & $586 \mathrm{i}$ & $842 \mathrm{i}$ & \\
\hline$E$ & 0.0 & -1.09 & -0.48 & 4.23 & -80.74 \\
\hline$E+\mathrm{ZPE}$ & 0.0 & -0.15 & 0.16 & 4.61 & -77.33 \\
\hline
\end{tabular}

$\mathrm{O}_{\mathrm{b}} \mathrm{O}_{\mathrm{c}}$ distance allowing the relaxations $1.80 \leq R_{\mathrm{HO}_{\mathrm{a}}} / \mathrm{a}_{0} \leq 1.90$, $2.45 \leq R_{\mathrm{O}_{\mathrm{a}} \mathrm{O}_{\mathrm{b}}} / \mathrm{a}_{0} \leq 2.55$, and $100 \leq \theta_{\mathrm{HOO}} / \mathrm{deg} \leq 110$. The two reaction paths that lead to products labeled as $\mathbf{C 1}$ and $\mathbf{C 2}$ are shown in thick solid lines. In one of the reaction paths $(\mathbf{C 1})$, the oxygen approximates to the HOO molecule with an angle of $156^{\circ}$, leading to products without passing through a transition state. The other reaction path (C2) evolves from a van der Waals complex (M1-II) to a transition state (TS1-II) that after including the zero-point energy correction is $0.22 \mathrm{kcal} \mathrm{mol}^{-1}$ above the complex. The transition state TS1-II is $0.93 \mathrm{kcal}$ $\mathrm{mol}^{-1}$ below the reactants. Both reaction paths lead to M2-II as shown in Figure 4. This contour plot is a function of the $\mathrm{O}_{\mathrm{a}} \mathrm{O}_{\mathrm{b}}$ and $\mathrm{O}_{\mathrm{b}} \mathrm{O}_{\mathrm{c}}$ distances allowing the relaxations $1.80 \leq R_{\mathrm{HO}_{\mathrm{a}}} /$ $\mathrm{a}_{0} \leq 1.90,100 \leq \theta_{\mathrm{HOO}} / \mathrm{deg} \leq 110,60 \leq \theta_{\mathrm{OOO}} / \mathrm{deg} \leq 180$, and $0 \leq \phi_{\mathrm{HOOO}} / \mathrm{deg} \leq 180$. The M2-II minimum corresponds to the formation of a metastable $\mathrm{HO}_{3}$ complex (M2-II) that is 46.41 $\mathrm{kcal} \mathrm{mol}^{-1}$ below reactants. The formation of this complex is the rate determining step of the reaction. Such a complex evolves to a more stable minimum (M3-II) which is connected to M2II by a transition state (TS2-II) with a barrier height of 10.28 $\mathrm{kcal} \mathrm{mol}^{-1}$ relative to the $\mathrm{OH}+\mathrm{O}_{2}$ products. The geometries and frequencies associted with these stationary points are listed in Table 2. 


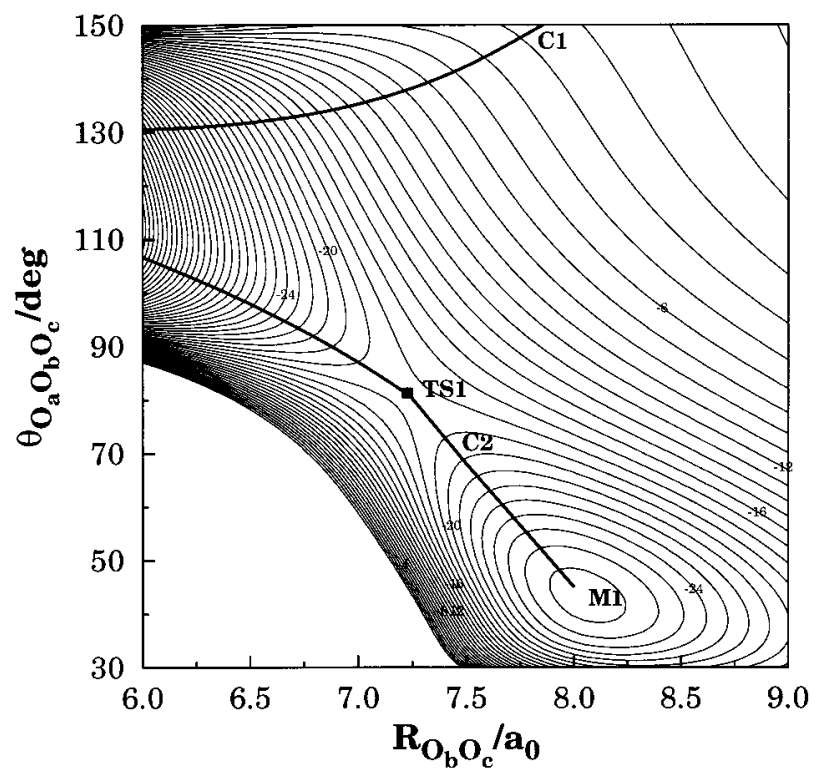

Figure 3. Potential energy surface for reaction $\mathbf{R 2}$ at large $R_{\mathrm{O}_{b} \mathrm{O}_{c}}$ distances. Energy contours are equally spaced by $0.05 \mathrm{kcal} \mathrm{mol}^{-1}$. The zero of energy corresponds to reactants. The two reaction paths are indicated by the thick solid lines.

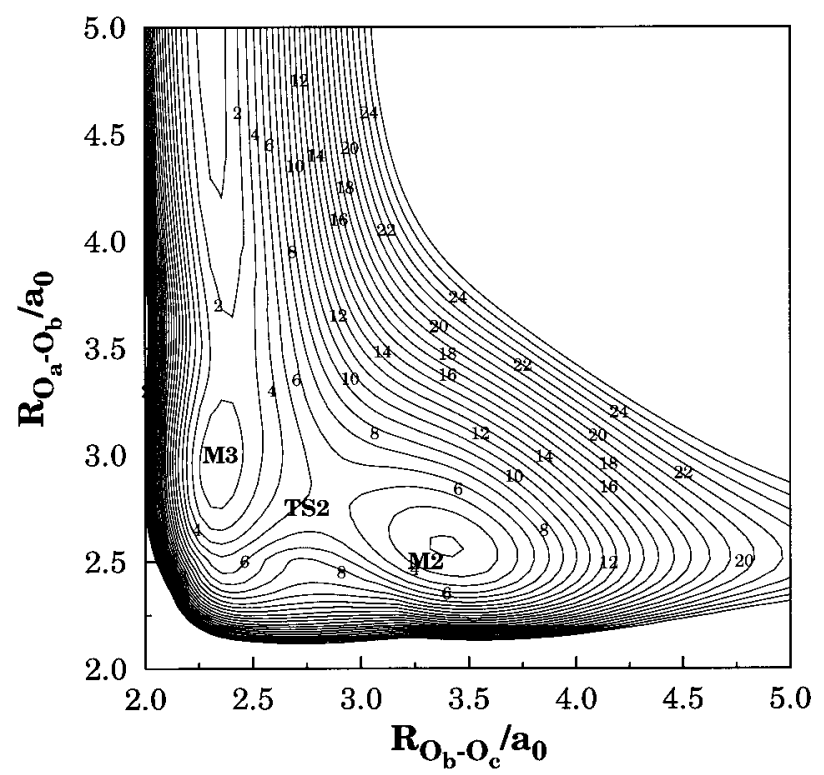

Figure 4. Potential energy surface for reaction $\mathbf{R 2}$ at short $R_{\mathrm{O}_{\mathrm{b}} \mathrm{O}_{\mathrm{c}}}$ distances. Energy contours are equally spaced by $2 \mathrm{kcal} \mathrm{mol}^{-1}$. The zero of energy corresponds to the reactants.

We now address the hydrogen abstraction mechanism. The reaction path for this mechanism first leads to the same van der Waals complex as for reaction $\mathbf{R} 2$ which is $1.38 \mathrm{kcal} \mathrm{mol}^{-1}$ below the reactants. It then evolves to products through a transition state lying $18.69 \mathrm{kcal} \mathrm{mol}^{-1}$ above the reactants. Contributions from this channel to reactivity can be neglected for most temperatures of interest. In fact, previous work $^{38}$ on the DMBE I surface has shown that this channel has little significance in comparison with the oxygen abstraction one, a result in agreement with the experimental findings.

\section{Methodology}

The thermal rate constants are calculated using VTST, ${ }^{41}$ namely, CVT and $\mu \mathrm{VT}$ theories, ${ }^{43}$ as implemented in POLYRATE 8.5. ${ }^{44}$ The CVT rate constant $k^{\mathrm{CVT}}(T)$ is defined at every temperature as the least forward flux of trajectories that cross any family of curves perpendicular to the MEP:

$$
k^{\mathrm{CVT}}(T)=\min k^{\mathrm{GT}}(T, s)
$$

where $s$ is the reaction coordinate and $k^{\mathrm{GT}}(T, s)$ is the rate constant for passage through the generalized transition state (GTS) that intersects the MEP at $s$. This is given by

$$
k^{\mathrm{GT}}(T, s)=\frac{\sigma}{h \beta} \frac{Q^{\mathrm{GT}}(T, s)}{Q_{\mathrm{R}}(T)} \exp \left[-\beta V_{\mathrm{MEP}}(s)\right]
$$

where $\sigma$ is the symmetry number, $\beta=k_{\mathrm{B}} T^{-1}, k_{\mathrm{B}}$ is the Boltzmann constant, $T$ is the temperature, $h$ is the Planck constant, and $Q^{\mathrm{GT}}(T, s)$ and $Q_{\mathrm{R}}(T)$ are the product of electronic, vibrational, rotational, and translational partition functions of the GTS and reactants, respectively; $V_{\mathrm{MEP}}(s)$ is the potential along the minimum energy path. It should be noted that the point along the MEP that meets eq 3, i.e., a point at which $s=$ $S_{*}^{\mathrm{CVT}}$, coincides with a maximum in the free energy $\Delta G(T$, $\left.s_{*}^{\mathrm{CVT}}\right)$. Thus, eq 3 can be rewitten as

$$
k^{\mathrm{CVT}}(T)=\frac{\sigma}{h \beta} \exp \left[-\beta \Delta G\left(T, s_{*}^{\mathrm{CVT}}\right)\right]
$$

On the other hand, the $\mu \mathrm{VT}$ rate constant is obtained from a sum-of-states criterion, which has been shown ${ }^{45}$ to be better than a minimum-density-of-states criterion. Specifically, the microcanonical sum of vibrational-rotational states $N_{\mathrm{vr}}^{\mu \mathrm{VT}}(E)$ at total energy less than $E$ is obtained from the minimum of the sum of vibrational-rotational states of the generalized transition states along the MEP. Thus

$$
N_{\mathrm{vr}}^{\mu \mathrm{VT}}(E)=\min N_{\mathrm{vr}}^{\mathrm{GT}}(E, s)
$$

with the rate constant being expressed as

$$
k^{\mu \mathrm{VT}}(T)=\frac{\sigma Q_{\mathrm{el}}^{\mathrm{GT}}(T) \int_{0}^{\infty} \exp (-\beta E) N_{\mathrm{vr}}^{\mu \mathrm{VT}}(E) \mathrm{d} E}{h Q_{\mathrm{R}}(T)}
$$

where $Q_{\mathrm{el}}^{\mathrm{GT}}(T)$ is the electronic partition function of the generalized transition state, considered here independent of $s$; the other variables are defined as in eq 4 . From the computational point of view, the effort necessary to obtain the microcanonical rate constant is bigger than for its canonical counterpart because it involves the evaluation of the thermal rate constant from integration of microcanonical rate constants.

The electronic degeneracy factor $f(T)$ for the oxygen atom assumes the form

$$
f(T)=\frac{1}{5+3 \exp \left(-\frac{227.6}{T}\right)+\exp \left(-\frac{325.9}{T}\right)}
$$

whereas it is 2 for atomic hydrogen and $\mathrm{HO}_{2}$ and 1 for the ozone molecule. Because the two terminal oxygen atoms of ozone are equivalent, the symmetry number $\sigma$ for $\mathbf{R} \mathbf{1}$ is 2 , whereas it is 1 for both reaction paths of reaction $\mathbf{R} 2$.

In the case of $\mathbf{R} \mathbf{1}$ and for the path $\mathbf{C 2}$ of reaction $\mathbf{R 2}$, the thermal rate constants were calculated by following the MEP obtained using the Page-McIver ${ }^{46}$ algorithm. A step size of 0.001 $\mathrm{a}_{0}$ has been employed, with Hessians calculated at every 0.01 $\mathrm{a}_{0}$. Path $\mathbf{C 1}$ of reaction $\mathbf{R} 2$ has no saddle point, and in the reactant valley, the potential is purely attractive. Thus, we cannot obtain the MEP in the same way as for the previous cases. To obtain such a path, we first moved the attacking oxygen atom 
TABLE 2: Same as Table 1 but for Reaction R2

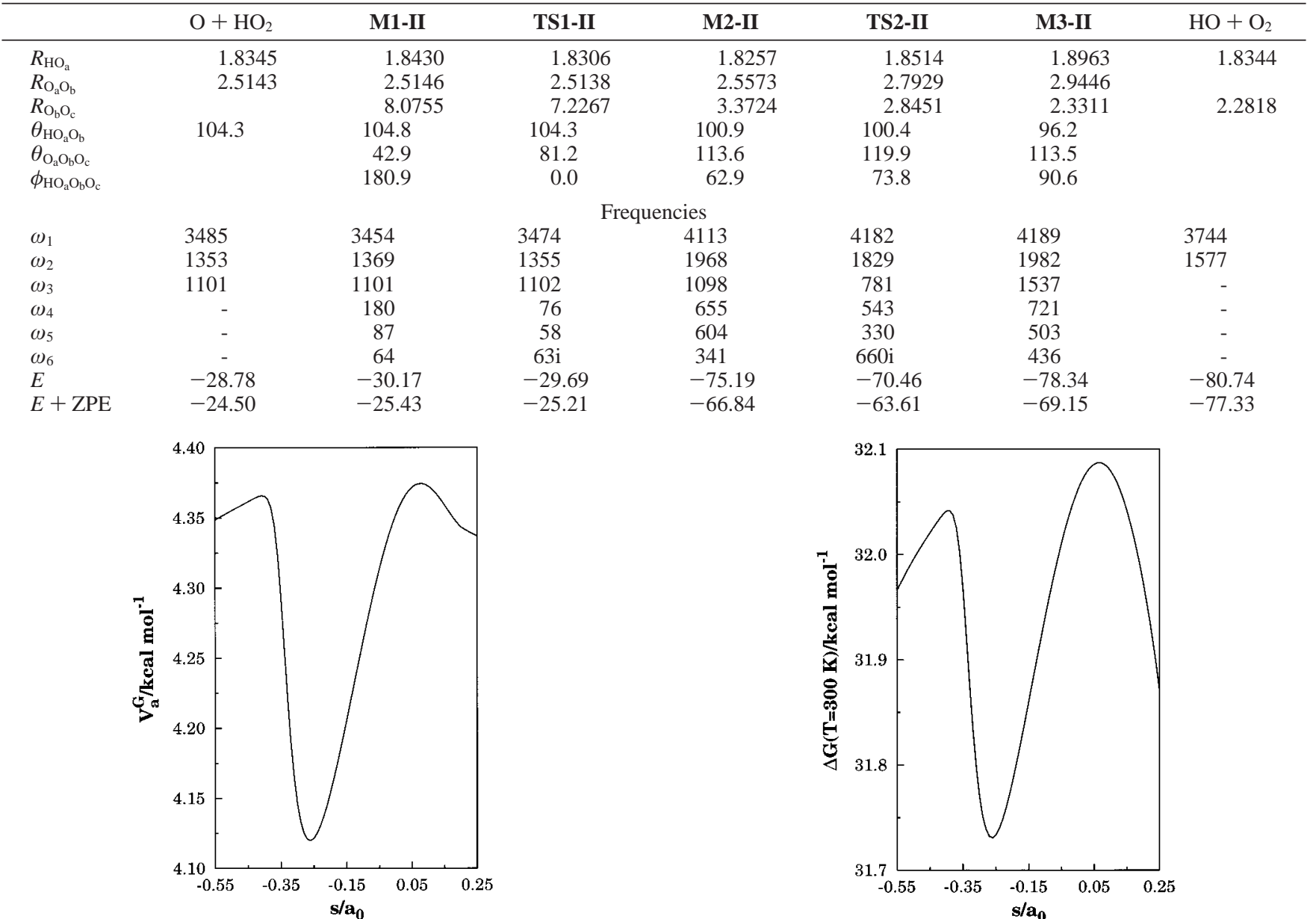

Figure 5. Vibrational adiabatic potential for reaction $\mathbf{R} 1$ as a function of the reaction path.

far away (about $9 \mathrm{a}_{0}$ ) from $\mathrm{HO}_{2}$, where the attacking angle $\angle \mathrm{O}_{\mathrm{a}} \mathrm{O}_{\mathrm{b}} \mathrm{O}_{\mathrm{c}}$ was optimized and found to be $156^{\circ}$. From this optimized geometry, we followed the gradient toward products using the Page-McIver algorithm with a step of $0.005 \mathrm{a}_{0}$ and Hessians calculated at every two steps.

\section{Results and Discussion}

Reaction $\mathbf{R} \mathbf{1}$ is a bimolecular reaction that presents a stable van der Waals complex (M1-I) between reactants and the transition state. After including the zero-point energy (ZPE), the van der Waals complex is still $0.15 \mathrm{kcal} \mathrm{mol}^{-1}$ below reactants and $0.31 \mathrm{kcal} \mathrm{mol}^{-1}$ more stable than the transition state. However, in the evaluation of the thermal rate constants, we have ignored this tiny minimum. In fact, the only maxima in the free energy between reactants and products were found to be close to the transition state TS1-I. Thus, we consider reaction $\mathbf{R} \mathbf{1}$ simply as

$$
\mathrm{H}+\mathrm{O}_{3} \rightarrow \mathrm{OH}+\mathrm{O}_{2}
$$

The vibrationally adiabatic ground-state potential $V_{\mathrm{a}}^{\mathrm{G}}(s)$ and Gibbs free energy $\Delta G$ at $T=300 \mathrm{~K}$ are depicted in Figures 5 and 6, respectively. As shown in Figure 6, there are two maxima in the free energy, a possibility which cannot be contemplated both by the CVT and $\mu$ VT methods, because the dividing surface is positioned at the highest maximum. Thus, both CVT and $\mu \mathrm{VT}$ ignore the recrossing because of the lowest maximum. One way to remedy this deficiency that overestimates the rate is to use
Figure 6. Gibbs free energy for reaction $\mathbf{R} 1$ at $T=300 \mathrm{~K}$ as a function of the reaction path.

the unified statistical theory (US). Originally proposed by Miller ${ }^{47}$ to describe reactions with more than one bottleneck, such a model interpolates between $\mu \mathrm{VT}$ (for the case of one bottleneck) and statistical phase space theory in the case of two bottlenecks. The sum of vibrational-rotational states is then given by

$$
N_{\mathrm{vr}}^{\mathrm{US}}(E)=N_{\mathrm{vr}}^{\mu \mathrm{VT}}(E) R^{\mathrm{US}}(E)
$$

where $R^{\mathrm{US}}(E)$ is the US model recrossing factor defined as

$$
R^{\mathrm{US}}(E)=\left(1+\frac{N_{\mathrm{vr}}^{\mu \mathrm{VT}}(E)}{N_{\mathrm{vr}}^{\min }(E)}-\frac{N_{\mathrm{vr}}^{\mu \mathrm{VT}}(E)}{N_{\mathrm{vr}}^{\max }(E)}\right)^{-1}
$$

where $N_{\mathrm{vr}}^{\mathrm{min}}$ is the second lowest minimum of $N_{\mathrm{vr}}^{\mathrm{GT}}(E, s)$ and $N_{\mathrm{vr}}^{\mathrm{max}}$ is the maximum of $N_{\mathrm{vr}}^{\mathrm{GT}}(E, s)$ that lies between the two minima. It should be noted that the US calculation is nonvariational, although it satisfies always $k^{\mathrm{US}}(T) \leq k^{\mu \mathrm{VT}}(T)$. In fact, for any reaction, $0.5 k^{\mu \mathrm{VT}}(T) \leq k^{\mathrm{US}}(T) \leq k^{\mu \mathrm{VT}}(T)$. This argument can be generalized to a canonical ensemble by defining canonical probabilities in terms of canonical-ensemble averages of the flux through these surfaces. ${ }^{48}$ The resulting canonical unified statistical rate (CUS) assumes the form

$$
k^{\mathrm{CUS}}(T)=k^{\mathrm{CVT}}(T) R^{\mathrm{CUS}}(T)
$$

with $R^{\mathrm{CUS}}(T)$ being the CUS recrossing factor. 


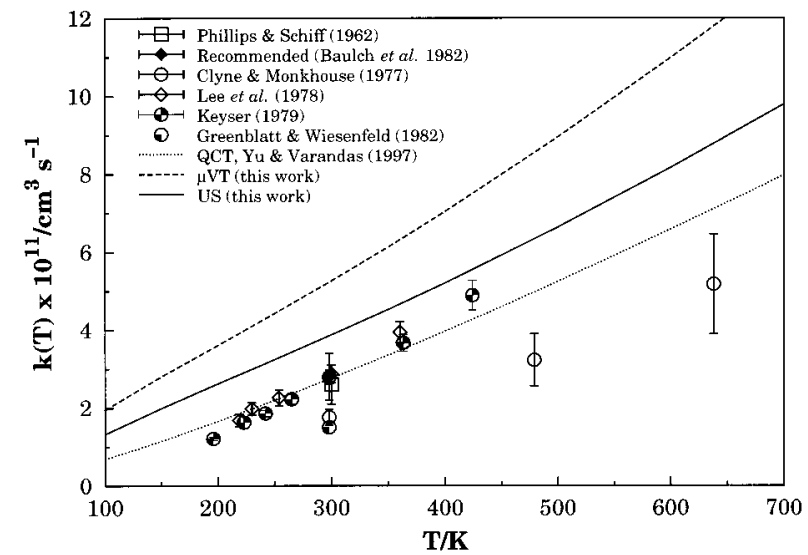

Figure 7. Arrhenius plot for reaction R1.

TABLE 3: Thermal Rate Constants, $k(T) \times 10^{11}$ in $\mathbf{c m}^{3} \mathrm{~s}^{-1}$, for Reaction R1

\begin{tabular}{ccccccrrrr}
\hline$T$ & CVT & $\mu$ VT & CUS & US & $T$ & CVT & $\mu$ VT & CUS & US \\
\hline 100 & 1.96 & 1.95 & 1.22 & 1.33 & 500 & 8.99 & 8.95 & 6.62 & 6.64 \\
200 & 3.61 & 3.61 & 2.53 & 2.62 & 600 & 11.07 & 10.97 & 8.16 & 8.16 \\
300 & 5.27 & 5.26 & 3.82 & 3.88 & 700 & 13.27 & 13.11 & 9.78 & 9.79 \\
400 & 7.06 & 7.04 & 5.18 & 5.21 & & & & &
\end{tabular}

The calculated rate constants for reaction $\mathbf{R} \mathbf{1}$ obtained by the VTST methods described in this paper are listed in Table 3. As seen, the CVT and $\mu$ VT rate constants differ only slightly above $T=500 \mathrm{~K}$. For instance, the difference between the two rates at $T=700 \mathrm{~K}$ is about $1 \%$. Thus, the location of the dividing surface at the maximum of free energy at every temperature in the CVT rate constants agrees well with the location of the set of dividing surfaces at every energy of the microcanonical rate constants. The "macroscopic" criterion of the CVT method is less accurate than the "microscopic" criterion in $\mu \mathrm{VT}$, and therefore, the CVT rate constants represent always an upper bound to the $\mu \mathrm{VT}$ rate constants. Both methods minimize the recrossing in the direction perpendicular to the MEP but do not eliminate it. Thus, they are an upper bound to classical trajectory calculations. In this case, the CUS and US methods involve a substantial improvement over the CVT and $\mu \mathrm{VT}$ methods because they take into account the recrossing because of the second maximum of the vibrationally adiabatic potential; see Figure 5. For instance, if the recrossing in both maxima were the same, then the US rate would be half of the $\mu \mathrm{VT}$ rate constant. For reaction R1, the recrossing because of the lower maximum decreases the rate by a factor of 0.71 and 0.67 at $T$ $=300 \mathrm{~K}$ by using the US and CUS methods, respectively. At this temperature, the two maxima in the free energy are located at $s_{\max _{1}}=-0.39 \mathrm{a}_{0}$ with $\Delta G=32.04 \mathrm{kcal} \mathrm{mol}^{-1}$ and $s_{\max _{2}}=$ $0.06 \mathrm{a}_{0}$ with $\Delta G=32.08 \mathrm{kcal} \mathrm{mol}^{-1}$, whereas the minimum is located at $s_{\min }=-0.26 \mathrm{a}_{0}$. The second maximum is the one considered in the canonical and microcanonical evaluation of the rate constants. As shown in Figure 7 , the $\mu \mathrm{VT}$ and CVT rate constants are about 2 times larger than the QCT values. The US and the CUS rate constants lead to substantial improvement in the results giving similar results to $\mathrm{QCT}^{23,24}$ and the experiment. ${ }^{10-13,22}$ We should note that the tunneling contribution to the VTST rate constants has been found to be negligible even at low temperatures where the transmission coefficient calculated using the small-curvature tunneling scheme ${ }^{49}$ is found to be between 1.01 and 1.03 . The recomended experimental value at room temperature for the activation energy 22,37 is $E_{\mathrm{a}} \simeq$ $0.9 \mathrm{kcal} \mathrm{mol}^{-1}$, whereas the QCT and US values are 0.75 and $0.64 \mathrm{kcal} \mathrm{mol}^{-1}$, respectively. Thus, the experiment predicts a larger slope than the theoretical calculations, and probably a
TABLE 4: Thermal Rate Constants, $k(T) \times 10^{11}$ in $\mathrm{cm}^{3} \mathrm{~s}^{-1}$, for Reaction $\mathbf{R 2}^{a}$

\begin{tabular}{rccccc}
\hline & & & & & \multicolumn{2}{c}{$k_{2}=$} \\
$T$ & $\mathrm{R}_{\mathrm{O}_{\mathrm{b}} \mathrm{O}_{\mathrm{c}}}$ & $k_{\mathrm{C} 1}^{\mathrm{CVT} / \mathrm{RODS}}$ & $k_{\mathrm{C} 1}^{\mu \mathrm{VT} / \mathrm{RODS}}$ & $k_{\mathrm{C} 2}^{\mathrm{TST}}$ & $k_{\mathrm{C} 1}^{\mu \mathrm{VT} / \mathrm{RODS}}+k_{\mathrm{C} 2}^{\mathrm{TST}}$ \\
\hline 150 & 7.36 & 4.99 & 3.92 & 14.3 & 18.22 \\
200 & 7.08 & 4.88 & 3.78 & 6.61 & 10.39 \\
300 & 6.68 & 4.59 & 3.62 & 5.00 & 8.62 \\
400 & 6.42 & 4.40 & 3.56 & 4.77 & 8.33 \\
500 & 6.26 & 4.29 & 3.57 & 4.90 & 8.47 \\
700 & 6.02 & 4.25 & 3.65 & 5.52 & 9.17 \\
900 & 5.86 & 4.30 & 3.78 & 6.31 & 10.09 \\
1500 & 5.55 & 4.64 & 4.19 & 8.99 & 13.18
\end{tabular}

${ }^{a}$ The second column indicates the $\mathrm{O}_{b} \mathrm{O}_{c}$ distance (in $\mathrm{a}_{0}$ ) at which the free energy is maximum.

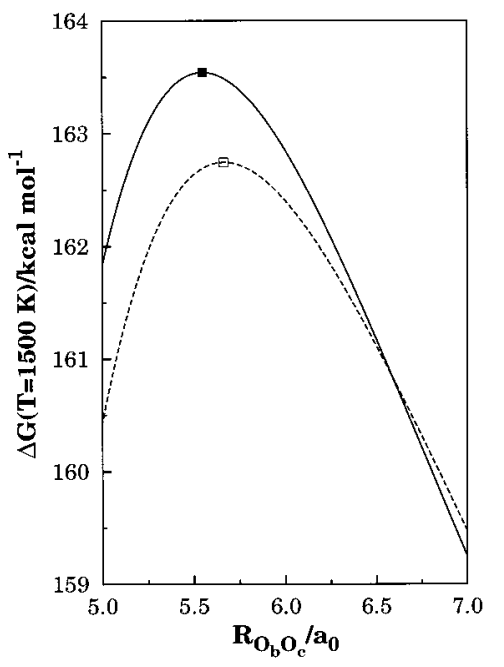

Figure 8. Gibbs free energy for reaction $\mathbf{R 2}$ as a function of the $\mathrm{O}_{b} \mathrm{O}_{c}$ distance at $T=1500 \mathrm{~K}$ for CVT (dashed line) and CVT/RODS (solid line) methods. For both methods, the location of the maximum of the free energy is indicated by a square symbol.

slight modification in the entrance channel of the DMBE potential energy surface would improve the results.

Reaction R2 was also studied with the methods described above. As mentioned in section 3, we found two reaction paths that lead to products. Path $\mathbf{C 1}$ has no transition state, and the potential toward products is purely attractive. The path shown in Figure 3 results from following the gradient from reactants to M1-II. This is the rate determining step of the reaction because the process from M1-II to products is much faster. The potential energy surface at large $\mathrm{O}_{b} \mathrm{O}_{c}$ distances is very flat, and it may be difficult to find the best dividing surface at every temperature. To circumvent this problem, we have used in conjunction with the CVT and $\mu \mathrm{VT}$ methods an algorithm that reorients the generalized-transition-state-theory dividing surface $(\mathrm{RODS})^{50}$ on the basis of information of geometries, gradients, and Hessians along the reaction path. The purpose of doing this is to find the orientation of the dividing surface that maximizes the free energy. The values of rate constants with the CVT and $\mu \mathrm{VT}$ with the RODS algorithm together with the value the $\mathrm{O}_{\mathrm{b}} \mathrm{O}_{\mathrm{c}}$ distance that maximizes the free energy are listed in Table 4. Figure 8 illustrates the free energy profile with and without the RODS algorithm at temperature $T=1500 \mathrm{~K}$. At this temperature, $k^{\mu \mathrm{VT}}=5.23 \times 10^{-11}$, whereas $k^{\mu \mathrm{VT} / \mathrm{RODS}}=4.19 \times 10^{-11}$ $\mathrm{cm}^{3} \mathrm{~s}^{-1}$ which represents a reduction by a factor of 0.8 . In fact, the ratios between the CVT/RODS and $\mu$ VT/RODS rate constants are between 1.11 and 1.27.

Path $\mathbf{C 2}$ has a transition state, and as for reaction R1, we have ignored the van der Waals complex in the evaluation of 


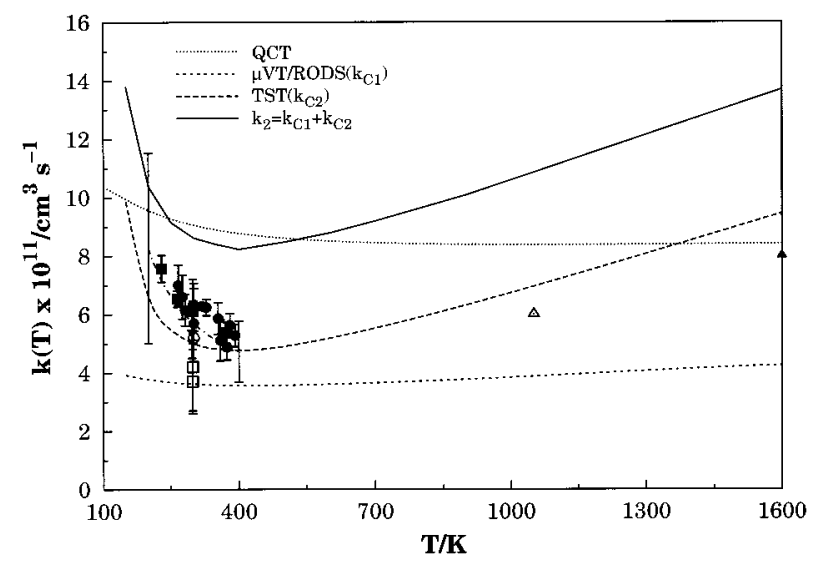

Figure 9. Arrhenius plot for reaction R2. Key for experimental values: $O$, ref $35 ; \mathbf{\square}, \operatorname{ref} 9 ; \square, \operatorname{ref} 31 ; \nabla, \operatorname{ref} 33 ; \nabla, \operatorname{ref} 32 ; 1 \bullet, \operatorname{ref} 34$; $\Delta$, ref 53; $\Delta$, ref 52. QCT calculations are from ref 38 . The dash-dot line represents the recommended experimental correlation ${ }^{37}$ with the error bars at 200 and $400 \mathrm{~K}$.

the rate constants because no maximum in the free energy was found between reactants and the complex M1-II. Besides, the maximum of the free energy coincided with the transition state at all the temperatures studied, so conventional transition state theory suffices in this case. The lowest frequency at the transition state $\left(58 \mathrm{~cm}^{-1}\right)$, corresponds to an out-of-plane motion of the hydrogen and is interesting to see the effect over the thermal rate constant when this mode is considered as a hindered rotor. Specifically, the partition function was evaluated using the $R_{\omega}$ scheme, in which the frequency corresponds to the outof-plane normal mode and the moment of inertia is obtained by a rectilinear model; for details, see ref 51 . The rate constants obtained by this scheme are listed in Table 4. At low temperatures there is not much difference whether this frequency is considered as a hindered rotor or a harmonic oscillator, but at high temperatures both rate constants differ substantially. For instance, at $T=1500 \mathrm{~K}$, the rate constant at which all modes are treated as harmonic oscillators is $14.2 \times 10^{-10} \mathrm{~cm}^{3} \mathrm{~s}^{-1}$, a factor of 1.6 times larger than the value listed in Table 4 .

For reaction $\mathbf{R 2}$, the total rate constant is the sum of the rate constants of the two individual reaction paths. All of them are plotted in Figure 9. As shown in Table 4, there is a displacement of the maximum of the Gibbs free energy toward shorter $R_{\mathrm{O}_{\mathrm{b}} \mathrm{O}_{\mathrm{c}}}$ distances when the temperature increases. This can be explained on the basis of entropic and enthalpic factors. For this reaction, at a given temperature, both the difference in enthalpy $\Delta H$ and entropy $\Delta S$ between a point along the steepest descent and the free rotating reactants are negative, and both functions decrease at shorter $R_{\mathrm{O}_{\mathrm{b}} \mathrm{O}_{\mathrm{c}}}$ distances. The maximum of $\Delta G=\Delta H-T \Delta S$ corresponds to the maximum of the difference between the two opposing factors. When the temperature increases, the entropic factor dominates and the maximum of the free energy moves to shorter $R_{\mathrm{O}_{\mathrm{b}} \mathrm{O}}$ distances. Therefore, the behavior of the rate constants for path $\mathbf{C 1}$ is typical of reactions that are dominated by capture; that is, the rate constant decreases or remains almost unaltered with temperature. The measurements by Day et al. ${ }^{52}$ at $T=1050 \mathrm{~K}$ and by Peeters and Mahnen ${ }^{53}$ at $T=1600 \mathrm{~K}$ predict an increase of the rate constant at high temperatures. The calculated activation energy with the $\mu$ VT/RODS method increases sligtly with temperature, being close to zero until $T$ $=900 \mathrm{~K}$ and with a value of $0.64 \mathrm{kcal} \mathrm{mol}^{-1}$ at $T=1500 \mathrm{~K}$. This increase is much slighter as for the experiment, so the experimental behavior is difficult to explain from the point of view of reaction path $\mathbf{C 1}$, but it can be explained by taking into account the alternative reaction path $\mathbf{C 2}$. For path $\mathbf{C 2}$, the rate constant decreases at low temperatures, and, e.g., at $T=$ $200 \mathrm{~K}$, the calculated TST energy of activation is $E_{\mathrm{a}}=-0.43$ $\mathrm{kcal} \mathrm{mol}^{-1}$. The energy of activation is zero at about $T=400$ $\mathrm{K}$, becoming positive at higher temperatures with a value of $2.3 \mathrm{kcal} \mathrm{mol}^{-1}$ at $1500 \mathrm{~K}$. A negative energy of activation at low temperatures involves a negative enthalpic contribution to the reaction, given that for a bimolecular reaction $E_{\mathrm{a}}=\Delta H+$ $2 R T$, with $R$ being the universal constant of ideal gases. At low temperatures, the negative slope of the Arrhenius plot is typical of a capture-like reaction, which is a consequence of having a transition state lower in energy than reactants. As the temperature increases, the contribution from the entropic factor, which is negative and with almost a constant value of $\Delta S \simeq-110 \mathrm{cal}$ $\mathrm{mol}^{-1} \mathrm{~K}^{-1}$ at all temperatures studied, becomes more important. Such a factor makes the rate constants increase with temperature, whereas the factor $2 R T$ makes the energy of activation positive at high temperatures. One may also speculate that such an increase in the rate constats may be due to the opening of a new reactive channel. For example, Setokuchi et al. ${ }^{42}$ pointed out that at high temperatures the oxygen atom may also attack the hydrogen atom in $\mathrm{HO}_{2}$, with a significant contribution to the overall rate. This issue cannot be corroborated from the present DMBE I potential energy surface, because the barrier height for this process is $18.6 \mathrm{kcal} \mathrm{mol}^{-1}$, giving a negligible contribution to the overall rate constant.

To summarize, the VTST rate constants are seen to compare reasonably well with the experiment and with QCT calculations for both reactions. It should be noted that VTST gives an upper bound to classical trajectories but not to quasiclassical ones, although such a relative positioning is corroborated by the present results for both reactions. On the basis of the present VTST calculations, one may conjecture that a better agreement with experiment for reaction $\mathbf{R} \mathbf{2}$ could be obtained if the DMBE I potential energy surface were modified to eliminate the reaction path C1. However, this assertion is difficult to prove because deviations of VTST from the experiment for both reactions may be due to anharmonicity, which may be important for lowfrequency modes or to contributions from other electronic states $^{23}$ that are known to cross the ground state.

\section{Conclusions}

We have employed VTST to calculate the thermal rate constants for reactions $\mathrm{H}+\mathrm{O}_{3} \rightarrow \mathrm{OH}+\mathrm{O}_{2}$ and $\mathrm{O}+\mathrm{HO}_{2} \rightarrow$ $\mathrm{OH}+\mathrm{O}_{2}$ using the DMBE I potential energy surface for ground state $\mathrm{HO}_{3}$. Results have been obtained using various forms of the theory, namely, $\mu \mathrm{VT}$, CVT, US, and CUS. Of these, the CUS and US results have been found to compare best with those of QCT and the experiment for reaction $\mathbf{R 1}$, because this reaction presents two maxima of the free energy along the MEP. The present VTST calculations predict that reaction $\mathbf{R 2}$ occurs by oxygen abstraction with contributions from two reaction paths. One reaction path shows no transition state and corresponds to an angle of attack of about $155^{\circ}$. In this case, both CVT and $\mu$ VT methods have been used together with an algorithm that reorients the dividing surface to maximize the Gibbs free energy. The other reaction path presents a shallow transition state that is below reactants, and the rate constants were calculated within the conventional TST by treating the lowest frequency mode as a hindered rotatation. For this reaction too, the VTST results are found to agree reasonably well with QCT calculations and experiment, explaining the behavior of the rate constant with temperature in the range of 200-1600 $\mathrm{K}$. Given the modest cost of such calculations, they may offer an alternative route for testing potential energy surfaces. 
Acknowledgment. This work has the support of Fundação para a Ciência e Tecnologia, Portugal, under Programs PRAXIS XXI and SAPIENS.

\section{References and Notes}

(1) Crutzen, P. Science 1997, 277, 1951.

(2) Bates, D. R.; Nicolet, M. J. Geophys. Res. 1950, 55, 301.

(3) Herzberg, G. J. R. Astron. Soc. Canada 1951, 45, 100.

(4) Meinel, A. B. Astrophys. J. 1950, 111, 555.

(5) Meinel, A. B. Astrophys. J. 1950, 112, 120.

(6) Charters, P. E.; Macdonald, R. G.; Polanyi, J. C. Appl. Opt. 1971 $10,1747$.

(7) Anlauf, K. G.; Macdonald, R. G.; Polanyi, J. C. Chem. Phys. Lett. 1968, $1,619$.

(8) Polanyi, J. C.; Sloan, J. J. Int. J. Chem. Kinet. Symp. 1975, 1, 51.

(9) Keyser, L. F. J. Phys. Chem. 1982, 86, 3439.

(10) Clyne, M. A. A.; Monkhouse, P. B. J. Chem. Soc., Faraday Trans. 2 1977, 73, 298

(11) Phillips, L. F.; Schiff, H. I. J. Chem. Phys. 1962, 37, 1233.

(12) Lee, J. H.; Michael, J. V.; Payne, W. A.; Stief, L. J. J. Chem. Phys. 1978, 69,350

(13) Greenblatt, G. D.; Wiesenfeld, J. R. J. Geophys. Res. 1982, 87, 11145 .

(14) Finlayson-Pitts, B. J.; Kleindienst, T. E.; Ezell, M. J.; Toohey, D. W. J. Chem. Phys. 1981, 74, 4533.

(15) Washida, N.; Akimoto, H.; Okuda, M. J. Chem. Phys. 1980, 72 5781.

(16) Finlayson-Pitts, B. J.; Kleindienst, T. E. J. Chem. Phys. 1979, 70, 4804 .

(17) Howard, C. J.; Finlayson, B. J. J. Chem. Phys. 1980, 72, 3842

(18) Force, A. P.; Wiesenfeld, J. R. J. Chem. Phys. 1981, 74, 1718.

(19) Ohoyama, H.; Kasai, T.; Yoshimura, Y.; Kuwata, H. Chem. Phys. Lett. 1985, 118, 263.

(20) Klenerman, D.; Smith, I. W. M. J. Chem. Soc., Faraday Trans. 2 $1987,83,229$

(21) Steinfeld, J. I.; Adler-Golden, S. M.; Gallagher, J. W. J. Phys. Chem. Ref. Data 1987, 16, 911.

(22) Baulch, D. L.; Cox, R. A.; Crutzen, P. J.; Hampson, R. F., Jr.; Kerr, J. A.; Troe, J.; Watson, R. T. J. Phys. Chem. Ref. Data 1982, 11 , 327.

(23) Varandas, A. J. C.; Yu, H. G. Mol. Phys. 1997, 91, 301.

(24) Yu, H. G.; Varandas, A. J. C. J. Chem. Soc., Faraday Trans. 1997, 93, 2651.

(25) Szichman, H.; Baer, M.; Varandas, A. J. C. J. Phys. Chem. 1997, $101,8817$.

(26) Szichman, H.; Baer, M.; Varandas, A. J. C. J. Phys. Chem. 1998, 102,8909
(27) Szichman, H.; Varandas, A. J. C. J. Phys. Chem. 1999, 103, 1967.

(28) Varandas, A. J. C. Int. Rev. Phys. Chem. 2000, 19, 199.

(29) Steinfeld, J. I.; Francisco, J. S.; Hase, W. L. Chemical Kinetics and Dynamics; Prentice Hall: Englewood Cliffs, NJ, 1989.

(30) Weisman, M.; Shum, L. S. G.; Heneghan, S. P.; Benson, S. W. J. Phys. Chem. 1981, 85, 2863.

(31) Hack, W.; Preuss, A. W.; Temps, F.; Wagner, H. Ber. BunsenGes. Phys. Chem. 1979, 83, 1275.

(32) Sridharan, U. C.; Qiu, L. X.; Kaufman, F. J. Phys. Chem. 1982, $86,4469$.

(33) Ravishankara, A. R.; Wine, P. H.; Nicovich, B. M. J. Chem. Phys. 1983, 78, 6629 .

(34) Brune, W. H.; Schwab, J. J.; Anderson, J. G. J. Phys. Chem. 1983, $87,4503$.

(35) Nicovich, J. M.; Wine, P. H. J. Phys. Chem. 1987, 91, 5118.

(36) Sridharan, U. C.; Klein, F. S.; Kaufman, F. J. Chem. Phys. 1985, $82,592$.

(37) Atkinson, R.; Baulch, D. L.; Cox, R. A.; Hampson, R. F., Jr.; Kerr, J. A.; Troe, J. J. Phys. Chem. Ref. Data 1992, 21, 1125.

(38) Wang, W.; González-Jonte, R.; Varandas, A. J. C. J. Phys. Chem. 1998, 102, 6935.

(39) Varandas, A. J. C.; Szichman, H. Chem. Phys. Lett. 1998, 295, 113.

(40) Varandas, A. J. C. Adv. Chem. Phys. 1988, 74, 255.

(41) Truhlar, D. G.; Isaacson, A. D.; Garrett, B. C. In Theory of Chemical Reaction Dynamics; Baer, M., Ed.; CRC Press: Boca Raton, FL, 1985; p 65.

(42) Setokuchi, O.; Sato, M.; Matuzawa, S. J. Phys. Chem. A 2000, 104, 3204.

(43) Garrett, B. C.; Truhlar, D. G. J. Phys. Chem. 1979, 83, 1053.

(44) Corchado, J. C.; Chuang, Y.-Y.; Fast, P. L.; Villa, J.; Hu, W.-P ; Liu, Y.-P.; Lynch, G. C.; Nguyen, K. A.; Jackels, C. F.; Melissas, V. S.; Lynch, B. J.; Rossi, I.; Coitino, E. L.; Fernandez-Ramos, A.; Steckler, R.; Garrett, B. C.; Isaacson, A. D.; Truhlar, D. G. POLYRATE, version 8.5; University of Minnesota: Minneapolis, MN, 2000.

(45) Garrett, B. C.: Truhlar, D. G. J. Chem. Phys. 1979, 70, 1593.

(46) Page, M.; J. W. McIver, J. J. Chem. Phys. 1988, 88, 922.

(47) Miller, W. H. J. Chem. Phys. 1976, 65, 2216.

(48) Garrett, B. C.; Truhlar, D. G. J. Chem. Phys. 1982, 76, 1853.

(49) Liu, Y.-P.; Lynch, G. C.; Truong, T. N.; Lu, D.; Truhlar, D. G. J. Am. Chem. Soc. 1993, 115, 2408.

(50) Villa, J.; Truhlar, D. G. Theor. Chem. Acc. 1997, 97, 317.

(51) Chuang, Y.-Y.; Truhlar, D. G. J. Chem. Phys. 2000, 112, 1221.

(52) Day, M. J.; Thompson, K.; Dixon-Lewis, G. Symp. (Int.) Combust. 1972, 14, 47

(53) Peeters, J.; Mahnen, G. Symp. (Int.) Combust. 1972, 14, 133. 